\title{
A formação do professor da Educação de Jovens e Adultos: um processo contínuo e reflexivo
}

Paola Andressa Scortegagna Mestranda do Programa de Pós-Graduação - UEPG. Ponta Grossa - PR [Brasil] paola_scortegagna@hotmail.com

Rita de Cássia da Silva Oliveira Doutora em Filosofia e Ciências da Educação - Universidade Santiago de Compostela; Professora do Programa de Pós-Graduação - UEPG. Ponta Grossa - PR [Brasil] soliveira13@uol.com.br
Este artigo apresenta algumas reflexões acerca da formação docente de um segmento de ensino muitas vezes esquecido, a Educação de Jovens e Adultos. Assim, observa-se a necessidade de repensar o desenvolvimento docente de modo geral, analisando o paradigma profissional-educacional: a formação do professor reflexivo. A reflexão sobre a prática implica questioná-la, levando a intervenções e mudanças: conhecimento pela análise. Atualmente, as mudanças requerem da escola o repensar das ações, pois esta necessita responder criticamente aos desafios gerados pelo capitalismo e pela globalização neoliberal nela repercutida. É somente com participação ativa e crítica no ambiente escolar que se contribuirá para o desenvolvimento do conhecimento escolar, que será gerado na interação das ações desenvolvidas. O apoio da comunidade é decisivo, tanto nas conquistas quanto no próprio aproveitamento escolar.

Palavras-chave: Educação de jovens e adultos.

Formação. Professores. 


\section{Introdução}

Atualmente, busca-se alargar, quantitativamente, as vagas na Educação de Jovens e Adultos (EJA) para diminuir a taxa de analfabetismo em nosso país, isto é, o objetivo principal é escolarizar o maior número de jovens e adultos possível. Porém, em meio à tentativa de propiciar o acesso desses sujeitos à escola, torna-se necessário questionar a formação docente dos profissionais que atuam nessa área.

Pode-se observar a crescente preocupação em alfabetizar os sujeitos marginalizados (SAVIANI, 2003), mas essa preocupação se efetiva na sua submissão à escola ou a algum programa educativo. No entanto, não se levam em consideração as condições de atendimento dessas pessoas nas instituições ou programas em que estão inseridas, nem há uma preparação, na maioria dos casos, para a formação específica dos professores que irão trabalhar nesse processo de alfabetização.

Dessa maneira, observa-se a ineficácia de diversos programas e projetos relacionados à EJA, em nosso país, como a quantidade de analfabetos funcionais que, mesmo submetidos às instituições ou programas de EJA, não compreendem textos simples e nem conseguem grafar o próprio nome.

Diante dessa situação, não se pode julgar esses indivíduos como incapazes de aprender ou como não alfabetizáveis. Deve-se repensar a Educação de Jovens e Adultos, suas diretrizes e parâmetros e, principalmente, investir na qualificação docente dos profissionais que atuam nessa área. Assim, o professor não só precisa ter acesso a uma formação inicial voltada para esse campo de ensino, como também, durante sua atuação, necessita de uma formação continuada em serviço, mas por isso, é necessário repensar a formação do professor de um modo geral, analisando o novo paradigma profissional e educacional: a formação do professor reflexivo. Os desafios atuais, ligados ao trabalho docente, abrem caminho à necessidade de reflexão sobre os processos de formação desse profissional, a quem se possibilita um novo modo de ser e estar na profissão.

$\mathrm{Na}$ atualidade, não se concebe mais a formação de professores por meio do paradigma da "racionalidade técnica” (PÉREZ GÓMEZ, 1995, p. 49), na qual a relação entre o profissional e a prática por ele desenvolvida ocorre de maneira desarticulada, uma vez que a teoria é de suma importância e seguida rigorosamente pelo professor durante sua ação pedagógica. Esse arquétipo parece conduzir o docente ao despreparo, sem que compreenda a realidade escolar da qual fará parte, pois esta se apresenta muito distinta das teorias repassadas, as quais visavam fornecer subsídios elaborados para a solução de problemas. Dessa maneira, a racionalidade técnica defende a idéia de que é possível aos profissionais solucionar problemas mediante a seleção dos meios técnicos.

Ao analisar essa problemática, Schön (1992, p. 66) afirma que os profissionais resolvem suas dificuldades mediante a aplicação da teoria e da técnica. $\mathrm{O}$ aspecto fundamental dessa concepção profissional é definido pela disponibilidade de uma ciência aplicada, que permita o desenvolvimento de procedimentos técnicos para a análise e diagnóstico dos problemas e para seu tratamento e solução.

A conseqüência é que, quando se esgotam o repertório e os instrumentos construídos como referenciais, o profissional não sabe como resolver determinadas situações, uma vez que as teorias se apresentam de maneira organizada e sistemática, e, na prática, existem problemas di-

Dialogia, São Paulo, v. 7, n. 1, p. 77-84, 2008. 
ferentes daqueles apresentados pelos livros, principalmente na EJA, programa em que ocorrem diferentes situações, às quais nenhum manual será capaz de responder.

Diante desse quadro, surge a racionalidade prática, novo paradigma de formação que, por meio de reflexão e pesquisa, busca estabelecer a relação entre o conhecimento e a prática pedagógica, em razão de o modelo de racionalidade técnica revelase incapaz de resolver tudo o que é imprevisível, que não é regulado pela aplicação de regras definidas para alcançar resultados já previstos, ou seja, são situações em que regras técnicas e cálculo não dão respaldo às soluções.

Por isso, é necessário possibilitar ao professor a capacidade de refletir sobre sua atuação profissional, objetivando entender a forma como se apresentam os problemas da prática, uma vez que na EJA há uma diversidade de situações problemáticas relacionadas aos contextos social, político e econômico que estão co-relacionados aos problemas da prática pedagógica em si.

Mesmo que essa questão seja aparentemente recente, a origem da perspectiva de reflexão remete a Dewey, que, já em 1933, defendia que esta consistia num exame ativo, persistente e cuidadoso de todas as crenças ou supostas formas de conhecimento à luz dos fundamentos que as sustentam e das conclusões a que tendam. "O ato reflexivo é questionador, baseado na vontade e intuição, implicando a busca de soluções lógicas e racionais para os problemas" (DEWEY, apud ZEICHNER, 1993, p. 28).

Vê-se, a partir disso, a necessidade de formar professores que reflitam sobre a própria prática, pois a reflexão será um instrumento de desenvolvimento do pensamento, da ação e do profissional.

Dessa maneira, o professor passa a ser visto como sujeito que constrói seus conhecimentos profissionais a partir de experiências e saberes, provindos de sua compreensão e reorganização, alcançadas pela interlocução entre teoria e prática.

Segundo Schön (1992), o conhecimento não se aplica à ação, mas está encarnado nela; por isso, há conhecimento na ação. O conhecimento é uma relação que se estabelece entre a prática e a teoria, numa forma de ver e interpretar o modo de agir no mundo.

A reflexão sobre a prática constitui seu questionamento, o que leva a intervenções e mudanças. A capacidade de questionamento e auto-questionamento é pressuposto para a reflexão: um constante processo de procura do vínculo entre o que se pensa e o que se faz. No entanto, refletir não é um processo rápido nem uma aprendizagem mecânica. Por isso, esse ato transforma o professor em profissional-pesquisador sobre a prática como construção contínua, pois a pesquisa é fundamental para seu desenvolvimento profissional. Assim, é necessário experimentar para propor novas compreensões ao caso examinado, transformando as diferentes situações em que se encontra, no âmbito da EJA.

Zeichner (1993, p. 18) afirma que "[. . .] a reflexão não é um conjunto de técnicas que possam ser empacotadas e ensinadas aos professores [...]" - o docente aprende com a própria experiência; conhecimento pela análise -, e complementa: "[...] ser reflexivo é uma maneira de ser professor."

A prática pedagógica, desenvolvida sob uma perspectiva reflexiva, não é uma prática que se realiza apenas circunscrita a seu contexto; está dimensionada num âmbito social maior, que representa também diferentes interesses e valores que a condicionam.

Ao estabelecer relações entre a prática reflexiva e a participação nos contextos sociais, o professor reflexivo estende suas atividades profissionais 
a uma situação social mais ampla, colaborando para uma mudança social e pública e ampliando o horizonte da compreensão crítica de sua atuação (CONTRERAS, 2002).

A partir desse contexto, refletir, pensar e aprender a pensar são idéias que precisam estar cada vez mais intrínsecas à vida do professor e exigem novas concepções nas formas de organização, gestão e ação das instituições de ensino, como também no processo educativo de jovens e adultos.

Precisa-se, então, lançar um novo olhar para essa comunidade na qual os profissionais envolvidos interagem, tornando essa realidade cada vez mais reflexiva, viva e dinâmica, para que desenvolva estratégias mais adequadas a cada momento em que surjam dificuldades. Diante disso, a reflexão deve ser pensada como prática social, por meio da qual um grupo de professores apóia e sustenta o crescimento dos outros.

Essa estrutura social que sustenta o trabalho dos professores em torno de um objetivo comum é chamada de comunidade de aprendizagem, que visa a um trabalho de colaboração coletiva, priorizando a capacidade de trabalhar em equipe, desenvolvendo um diálogo reflexivo sobre a aprendizagem e identificando seus problemas.

Para compreender o ambiente escolar como comunidade de aprendizagem, propõe-se a análise do significado dessa concepção para o entendimento da sua importância.

\section{Comunidades de aprendizagem}

Entende-se como comunidade de aprendizagem a estrutura social que sustenta o trabalho de um grupo de indivíduos na busca de um objetivo comum (AFONSO, 2001) e abriga um novo modelo de cultura e de organização educativa que suporta a mudança em contexto educativo. Esse modelo se manifesta pelo empenho contínuo dos envolvidos no trabalho colaborativo e pelo esforço em criar elementos significativos para essa comunidade.

O objetivo principal da comunidade de aprendizagem é a equipe, ou seja, trabalhar e aprender em grupo, levando em conta dificuldades de relacionamento, sobretudo nas organizações educativas.

Esse trabalho cooperativo, que se aplica numa espécie de diálogo reflexivo sobre a aprendizagem, também busca identificar os problemas e temas relacionados a ela (ARGYRIS, apud SCHÖN, 1996).

Segundo Cross apud Afonso (2001, p. 81), alguns aspectos são fundamentais para o trabalho nessas comunidades:

- Mudança de paradigma, pois estudos e experiências realizados sobre a aprendizagem revelam resultados significativos;

- Ambiente intelectual, social, cultural e psicológico facilita a aprendizagem e promove a interação e construção conjunta;

- Alternativa curricular aos modelos tradicionais de ensino aprendizagem, grupos de trabalho descentralizados que se organizam em comunidades, cuja meta é o apoio mútuo para o desenvolvimento de atividades construtivas de aprendizagem.

A comunidade de aprendizagem está em constante crescimento e renovação, pois todos os componentes refletem sobre o ensino, a aprendizagem e, sobretudo, a cultura, visto ser importante a promoção da aprendizagem com base na compreensão e na capacidade de transferência e aplicação desse conhecimento em diversos contextos. 
Portanto, as comunidades de aprendizagem fornecem uma infra-estrutura comum de aprendizagem acessível a todos, promovendo o desenvolvimento de competências e a construção social do conhecimento.

Por isso, pode-se perceber os elementos que distinguem, das outras comunidades, as de aprendizagem: poder distribuído, conhecimento socialmente construído e partilhado, atividades flexíveis, membros autônomos, níveis elevados de interação e colaboração, interesses e objetivos comuns.

O principal elemento das comunidades de aprendizagem é a criação de contextos em que se promovam a participação coletiva e a interação como suporte da reflexão. Esses contextos facilitam a interação promovendo a construção social do conhecimento e a dimensão social da aprendizagem. A construção é o centro da analise, dando lugar a novas formas de aprendizagem, promovendo atividades construtivas, colaborativas e continuadas, dando maior coerência aos conteúdos de aprendizagem e interação entre os membros da comunidade.

Nesse sentido, a aprendizagem colaborativa é o núcleo do funcionamento das comunidades de aprendizagem, pois visa à construção do conhecimento em atividades coletivas.

Esse modelo de comunidade de aprendizagem permite contribuir para o desenvolvimento de indivíduos capazes de formular hipóteses inovadoras e uma aprendizagem independente e contínua, para que participem ativamente na construção de organizações.

Isso só será possível se reorganizarmos os tradicionais modelos de ensino-aprendizagem nessas comunidades, promovendo um verdadeiro diálogo reflexivo entre todos os envolvidos, permitindo transformação das instituições acadêmicas em verdadeiras organizações que aprendem.
Diante disso, ao definir as comunidades de aprendizagem, observa-se a realidade das escolas como lugar de formação de indivíduos capazes de interagir entre si, participando de esforços comuns em que todos desempenhem papéis ativos e buscando mudanças para uma educação de alta qualidade.

Assim, os diferentes debates que acontecem a respeito da realidade organizacional das escolas contribuem significativamente para a compreensão da diversidade e interação dos processos de decisões no ambiente escolar.

Com as diversas mudanças ocorridas na maneira de gerir no ambiente escolar, para maior autonomização e atribuições mais democráticas nas formas de gestão, a qualidade das atividades educativas das escolas está cada vez mais dependente da qualidade do trabalho desenvolvido de acordo com as regulações internas dos estabelecimentos de ensino.

Tal qualidade depende da maneira como os envolvidos com tal processo negociam, discutem e tomam as decisões necessárias, definindo as normas e regras coletivas que regem a escola.

Dessa forma, segundo Santiago, apud Alarcão (2001), a escola também é um sistema de aprendizagem, a partir do momento em que seus atores estabelecem acordos para melhorar as capacidades e competências coletivas na resolução de problemas, interpretação e criação de normas que regulem os diferentes componentes do processo educativo. Essa interação, ocorrida ou não no interior das escolas, pode ser objeto de análise diante das diferentes atitudes diárias.

Atualmente, as mudanças requerem da escola o repensar das ações, pois esta necessita responder criticamente aos desafios gerados pelo capitalismo e pela globalização neoliberal nela repercutida. Dessa forma, é preciso uma reflexão sobre a reconstrução 
da escola, visando a uma ação coletiva por todos os envolvidos no universo escolar.

Assim, a escola, ao interagir com os demais envolvidos, possibilita uma aprendizagem organizacional, quando tenta corrigir os erros que detecta ao confrontar com a realidade os resultados esperados.

As organizações educativas são sistemas de aprendizagem organizacional, portanto precisam respeitar a autonomia dos seus profissionais, podendo questionar as formas tradicionais de organização, incentivando a reflexão sobre suas experiências e troca de idéias entre os envolvidos.

É claro que os educadores, em geral, enfrentam desafios de toda ordem, vivem sensações de desamparo, e a única saída se configura na formação de uma equipe de trabalho em que toda a comunidade escolar ofereça apoio profissional, construindo uma equipe de trabalho voltada ao coletivo.

Dessa forma, a escola tem a possibilidade de contribuir para a produção de um conhecimento transformador que propicia, segundo Grinspun (2003), uma compreensão crítica das condições sociais, de forma que o professor se torne o mediador do conhecimento, e o aluno, o sujeito de seu próprio desenvolvimento. Assim, a construção dessa escola busca, coletivamente, discutir as situações desafiadoras do cotidiano escolar, combatendo o isolamento e o individualismo.

Dessa maneira, a escola torna-se uma comunidade de pessoas que age, interage, aprende e se desenvolve como uma comunidade educativa viva e dinâmica que diversifica as estratégias, buscando atingir seus objetivos com qualidade.

Uma escola com tais características configura-se como reflexiva, assume-se como instituição educativa ciente do que quer e de que direção tomar. Portanto, nela não se concebe que seus membros sejam apenas executores de decisões tomadas por outros; há incentivo e mobilização para participação, diálogo, reflexão, iniciativa e novas ações. Assim, a instituição escolar deixa de viver um cotidiano repleto de contradições, conflitos e lutas e passa a desenvolver objetivos e metas comuns.

Nessa perspectiva, na luta pela defesa dos interesses convergentes, com todos os elementos envolvidos no processo educativo é que se forma a dinâmica entre a ação e a reflexão; o que se pretende fazer e colocar em prática.

Somente uma participação ativa e crítica no ambiente escolar contribuirá para o desenvolvimento do conhecimento da própria escola, que será gerado na interação das ações nela desenvolvidas. Assim, essa instituição, como um ambiente vivo, combinada às interações de uma visão real e compartilhada do caminho que se quer percorrer e onde se espera chegar, concretiza-se em uma organização aprendente.

Apesar das inúmeras vezes em que se ouve falar em mudanças, em posicionamento mais reflexivo, em uma escola sintonizada e comprometida com o pedagógico, não se pode esquecer que nada se transforma de forma isolada, como já foi dito. Para que isso ocorra, é necessário que tal proposta surja do consenso dos envolvidos com essa mudança, não só por meio de discursos, mas por um trabalho sério e comprometido.

\section{Formação docente}

Ao analisar o professor como sujeito de transformação, expõem-se os inúmeros obstáculos que ele encontra durante o trajeto de sua carreira; porém, acredita-se que, para contribuir com a mudança desse quadro, é preciso que o professor recupere, antes de tudo, sua auto-estima, organize-se

Dialogia, São Paulo, v. 7, n. 1, p. 77-84, 2008. 
e sensibilize a comunidade escolar quanto à busca de uma educação de qualidade.

O apoio da comunidade é decisivo tanto nas conquistas quanto no próprio aproveitamento escolar. É preciso também que a escola, como um todo, reveja sua forma de trabalho, propiciando trocas de informação, reflexões sobre as ações tomadas, os resultados obtidos e decisões coletivas das novas propostas.

Novamente, insiste-se na perspectiva do professor como sujeito de transformação, como aquele que acredita na possibilidade de mudança, superando o estado de descrença e de mero discurso, indo além das expectativas, valorizando os pequenos avanços e buscando, no coletivo, atingir as metas esperadas.

Portanto, é preciso que o professor exerça a capacidade de refletir, criticar e intervir para que as instituições educacionais gerem mudanças. Se o educador não começar a praticar sua função de agente da transformação, acaba se perdendo na trajetória profissional.

Ante os problemas, o professor, ao reconhecer seu desejo de intervir, começa a questionar-se diante das possibilidades de sua ação e da maneira que esta irá direcionar seu poder. Essa atitude constitui uma postura transformadora, uma vez que, a partir da compreensão da realidade, busca interferir no seu processo redirecionando sua ação.

Dessa forma, percebe-se que o professor detém um poder de ação que não se encontra pronto e acabado, mas que pode ser ampliado e redirecionado conforme a sua capacidade de atuação.

\section{Considerações finais}

Volta-se, por fim, a reforçar a idéia de que um professor reflexivo e transformador deve ultrapas- sar obstáculos que encontra no trajeto da mudança, acreditando na possibilidade de vencer as dificuldades encontradas, ou seja, as tentativas de inovação nas instituições educativas devem ser propostas, havendo uma nova forma de profissionalização do professor.

Segundo Ferreira (2000, p, 48-49),

[...] o ponto mais delicado de qualquer processo de mudança qualitativa é a capacitação de professores. As experiências demonstram, no entanto, que os processos de capacitação mais rápidos, profundos e bem sucedidos parecem ser aqueles em que se acompanha o professor em serviço.

Para que esse processo de formação ocorra, é preciso que o sujeito esteja aberto a ele, sinta necessidade e deseje sair do estado de imobilismo em que geralmente se encontra.

Por isso, é fundamental que o professor tome consciência do que faz, tenha uma visão crítica das atividades, dos procedimentos na sala de aula e dos valores culturais de sua função docente e adote, além da postura de transmissor, a de pesquisador.

\section{The teacher's formation of youth and adult education: a continuous and reflexive process}

This article presents considerations about teacher's formation, specifically the Youth and Adult Education program. Thus, we observed how it is necessary to think about the development of teacher's formation, analyzing the new professional and educational paradigm: the formation of the reflective teacher. Nowadays, the changes require the school to rethink its actions and to face the challenges of the capitalism and the neoliberal globalization present in the 
school. Also, the support of the community is decisive in the conquests and in the school exploitation.

Key words: Formation. Youth and adults education. Teachers.

\section{Referências}

AFONSO, A. P. Comunidades de aprendizagem: um modelo para gestão da aprendizagem. 2001. Dissertação (Mestrado)- Universidade de Coimbra, Portugal, 2001.

ALARCÃO, I. (Org.). Escola reflexiva e supervisão, uma escola em desenvolvimento e aprendizagem. Porto: Porto Editora, 2001.

CONTRERAS, J. A autonomia de professores. São Paulo: Cortez, 2002.

FERREIRA, N. S. C.; AGUIAR, M. A . da S. (Org.). Gestão da educação. São Paulo: Cortez, 2000.
GRINSPUN, M. P. S. Z.(Org.). Supervisão e orientação educacional. Perspectivas de integração na escola. São Paulo: Cortez, 2003.

NOBRE, D. Os discursos da/na construção do campo da formação contínua de alfabetizadores/ as e suas relações com o campo da formaçõa de alfabetizadores/as de pessoas jovens e adultas. [online]. Disponível em: <www.educacaoonline.pro.br/ os_discursos_da.asp $>$ Acesso em: 7 set.2005, 17:52:23.

PÉREZ GÓMEZ, A. I. Compreender e transformar o ensino. Tradução de Ernani F. da Fonseca Rosa. 4. ed. Porto Alegre: Artmed, 1995.

SAVIANI, D. Escola e democracia. São Paulo: Autores Associados, 2003.

SCHÖN, D. Formar professores como profissionais reflexivos. In: A. NÓVOA. Os professores e a sua formação. Lisboa: D. Quixote, 1992. p. 79-91.

ZEICHNER, K. A formação reflexiva de professores: idéias e práticas. Lisboa: Educa, 1993.

recebido em 20 abr. 2008 / aprovado em 25 maio 2008

Para referenciar este texto:

SCORTEGAGNA, P. A.; OLIVEIRA, R. de C. da S. A formação do professor da Educação de Jovens e Adultos: um processo contínuo e reflexivo. Dialogia, São Paulo, v. 7, n. 1, p. 77-84, 2008. 